\title{
Multi-threshold inertial switch for quantitative acceleration measurements
}

\author{
Qiu Xu, Fahimullah Khan, and Mohammad I. Younis
}

Abstract-This paper presents a multi-threshold inertial switch demonstrated experimentally and through simulation. A laterally-driven multi-threshold inertial switch based on SOIMUMPs has been fabricated. The device has been tested by a drop-table test system under different shock accelerations with various amplitudes and pulse widths. In addition to experimental data, finite element simulation has been used to further assess the device's performance. The designed switch is a 2-axis device capable of triggering in all directions in a single plane. This work demonstrates that the designed inertial switch with 3 threshold levels can perform quantitative acceleration measurements while saving power when not activated. The multi-threshold inertial switch can sense a shock range of $800 \mathrm{~g}-2600 \mathrm{~g}$. The same device principle can be extended for a higher number of bits. The axial disturbance performance shows that the inertial switch has high single-axial sensitivity and low axial cross-talk.

Index Terms-MEMS, multi-threshold, quantitative acceleration measurements, single-axial sensitivity

\section{Introduction}

$\mathrm{M}$ icro-electro-mechanical systems

(MEMS) accelerometers are widely used in many fields, such as consumer electronics, industrial products, video games, and vibration monitoring due to their small size, low cost, large volume production, and reliability. With the rapid development of the internet of things (IoT), inertia sensors are anticipated to be under even more tremendous demand. MEMS accelerometers are also implemented in switching/triggering algorithms, for example for alarming and safety applications, in which they communicate their data to controllers and decision units, which send out triggering commands to actuation units when the signal acceleration exceeds predetermined thresholds. In such systems, accelerometers are continuously powered, operating, and sending data, which poses challenges in terms of energy consumption and data processing. However in many IoT applications, for instance in remote areas and health applications, it may not be feasible or easy to replace batteries. Power becomes a great obstacle constraining significantly the usage of MEMS accelerometers in such modern applications and integrated systems.

The MEMS inertial switch, also called acceleration switch/trigger, is a kind of a passive device, which ideally consumes no power until an acceleration event is detected above a certain threshold. So it can be widely applied to long-lifetime systems in harsh and remote environments, such as in IoT, regardless of the limited power [1-5]. Compared to MEMS accelerometers, the inertial switch consumes ideally zero power under the normal inactive state and can provide substantial benefits in saving energy and prolonging battery life. Thus, the inertial micro switch is promising to be widely

The authors are with the Physical Sciences and Engineering Division, King Abdullah University of Science and Technology, Thuwal, 23955-6900, Saudi Arabia. Corresponding author: M. I. Younis, e-mail: Mohammad.Younis@kaust.edu.sa,ORCID:orcid.org/0000-0002-9491-1 838 used in remote monitoring systems [3, 6].

MEMS inertial switches are widely applied in many fields, such as military, automobiles, industrial transportation, handled devices, safety, and geriatric healthcare systems due to the advantages of miniaturization, low cost, large volume production, zero power consumption at a normal state, and resistivity to electromagnetic noise [7-16]. When the inertial switch is accelerated above the threshold value along the sensing direction, the movable electrode moves toward the stationary electrode touching it, which closes an external circuit [17-24].

In most cases, an inertia switch is designed to be trigged beyond a single acceleration threshold making them binary with on-off information. In other words, it can only show that the applied acceleration is lower or higher than the preset threshold level, but it cannot indicate quantitative information about how much acceleration the inertial switch is subjected to [25-27]. This kind of acceleration switch with a single threshold value can be referred to as a single bit digital accelerometer. In order to significantly reduce the power consumption, provide quantitative information of acceleration, and make use of the simplicity of inertia switch systems, it is of great advantage to design inertial switches with multi-threshold levels, which are able to provide quantitative acceleration measurements while saving power, i.e., multi-bit digital accelerometers.

For some applications, more information and classifications are needed on the various levels of acceleration and categories of shock. For example, for brain impact injuries, it makes big difference to inform that the patient has been subjected to a shock in the range of 100-150 g than just to indicate that the impact was above the threshold of $60 \mathrm{~g}$. Also, micro switches with multiple thresholds can be an important feature in applications such as portable devices. A comparison of the performance of different multi-threshold acceleration inertial switches is shown in Table I. In 1972, Frobenius et al. [28] first reported inertial switches, which are compatible with the integrated circuit technology. It is mainly composed of one 
proof mass, a set of contact pads, and multiple metal beams. The different lengths of the multiple metal beams result in different deflections of the beam's tip, and hence various thresholds when the device is subjected to an acceleration in the sensing direction ( $z$ direction). The threshold acceleration varies from $10 \mathrm{~g}$ to $100000 \mathrm{~g}$. The conventional way to detect different threshold levels is to integrate several single-threshold inertial switches with different threshold levels on a single chip. Currano et al. [29] provided a full chip that consists of five individual tri-axial inertial switches with different threshold levels. Their design can sense the acceleration in every side $(+x /-x /+y /-y)$ and above and below the proof mass $(+z /-z)$. The various angles traversed by the spiral spring leads to different elastic coefficients of the spring/mass system, which results in the various threshold levels. It can detect the acceleration magnitude ranging from $50 \mathrm{~g}$ to $250 \mathrm{~g}$. Selvakumar et al. [30] reported a threshold level detection microsystem, which is made up of an array of inertial switches with various threshold levels. These switches were fabricated by utilizing the bulk-silicon dissolved-wafer process. The process enables the switches to employ different silicon inertial masses. The range of threshold levels for the designs varies from $1.5 \mathrm{~g}$ to 1000 g. Reddy et al. [31] proposed a zero-power shock sensor of multiple threshold accelerations. The latching part on the proof mass has ten discrete latch positions, which can determine the different threshold levels. After every shocking event, the movable electrode is latching. The electrostatic actuator is used to reset and initiate the device by releasing the coupling between the latch part and proof mass. Their proposed shock sensor allows a threshold acceleration in a wide range from $20 \mathrm{~g}$ to $250 \mathrm{~g}$ with 10 threshold levels. However, such complexity in designs may limit its application. Varun et al. [26] demonstrated MEMS accelerometers that contain a proof mass and arrays of parallel electrostatic tuning electrodes that exert an assistive force on the proof-mass. The assistive force pulls the proof mass towards the stationary electrode, and then the gap size between the proof mass and the stationary electrode is reduced. Correspondingly, the acceleration threshold can be changed over a wide range. A two bits accelerometer has been successfully fabricated and demonstrated in the $0-1 \mathrm{~g}$ range. Most of the reported inertial switches are inertial switches with one threshold level [9, 11-13] and many of these devices are not resettable [32-34].

In this work, we have designed a lower power MEMS inertial threshold sensor with multiple thresholds, which can classify and provide more quantitative information on the acceleration level compared to the traditional binary switches. The inertial switch consists of a proof mass, a movable electrode, and three stationary electrodes that have different distances between the movable electrode and stationary electrode. The corresponding three switches can be turned ON and OFF in a sequential manner when the inertial switch is subjected to the different applied accelerations. Following a simple switching algorithm, the applied acceleration range is measured by the switches' state and acceleration digital output, which enables the detection of multiple threshold events over a wide operating range. In addition, the presented device is biaxial that can sense acceleration in each side of the proof mass $(+x /-x /+y /-y$ directions $)$. The designed inertial switch is optimized through analytical and finite element simulations.
Finally, the fabricated prototypes are tested by a dropping hammer system, which verify that the designed inertial switch can perform quantitative acceleration measurements and has high single-axial sensitivity and low axial cross-talk. The same device concept can be further enhanced and extended for higher resolution and higher bit digital quantitative acceleration measurements.

TABLE I

COMPARISON OF DIFFERENT MULTI-THRESHOLD INERTIAL SWITCHES

\begin{tabular}{|c|c|c|c|c|}
\hline $\begin{array}{l}\text { Sensing } \\
\text { acceleration } \\
\text { range }\end{array}$ & $\begin{array}{l}\text { Sensing } \\
\text { shock } \\
\text { direction }\end{array}$ & $\begin{array}{l}\text { Ease of design } \\
\text { (The number } \\
\text { of proof mass) }\end{array}$ & $\begin{array}{l}\text { Operation principle } \\
\text { Of multi-threshold } \\
\text { acceleration }\end{array}$ & Reference \\
\hline $10 \mathrm{~g}-100000 \mathrm{~g}$ & $-z$ & Simple (1) & $\begin{array}{l}\text { Different length of the } \\
\text { beam }\end{array}$ & [28] \\
\hline $1.5 \mathrm{~g}-1000 \mathrm{~g}$ & $-z$ & Complex (5) & $\begin{array}{l}\text { Different length of the } \\
\text { beam and mass }\end{array}$ & [29] \\
\hline $50 \mathrm{~g}-250 \mathrm{~g}$ & $\begin{array}{l}+x /-x /+y / \\
-y /+z /-z\end{array}$ & Complex (5) & $\begin{array}{l}\text { Different elastic } \\
\text { coefficient of the } \\
\text { spring }\end{array}$ & [30] \\
\hline $20 \mathrm{~g}-250 \mathrm{~g}$ & $-y$ & Complex (1) & $\begin{array}{l}\text { Depending on different } \\
\text { gaps between two } \\
\text { electrodes }\end{array}$ & [31] \\
\hline $0-1 \mathrm{~g}$ & $-x$ & Complex (1) & $\begin{array}{l}\text { Depending on assistive } \\
\text { force } \\
\text { of the tuning electrodes }\end{array}$ & [26] \\
\hline $800 \mathrm{~g}-2600 \mathrm{~g}$ & $\begin{array}{l}+x /-x / \\
+y /-y /\end{array}$ & Simple (1) & $\begin{array}{l}\text { Depending on different } \\
\text { gaps between two } \\
\text { electrodes }\end{array}$ & $\begin{array}{l}\text { Present } \\
\text { work }\end{array}$ \\
\hline
\end{tabular}

\section{DEVICE DESIGN AND THEORETICAL ANALYSIS}

\section{A. Structure Design}

It can be seen from Fig. 1(a) that the designed multi-threshold inertial switch mainly consists of movable electrodes (a group of three at each side) attached to the proof mass, which is suspended by four serpentine springs, and stationary electrodes corresponding to the first, second, and third acceleration thresholds. The device is a biaxial inertial switch that can sense acceleration in the $x$ and $y$ axes, and in both positive and negative directions for each axis. In this work for brevity, only $+y$ direction is discussed as the sensitive direction. Fig. 1(b) shows a close-up of the overlap and contact area of gaps $x_{1}, x_{2}, x_{3}$ between the movable electrode and the stationary electrode 1,2 , and 3 with values $5 \mu \mathrm{m}, 10 \mu \mathrm{m}$, and $15 \mu \mathrm{m}$, respectively.

\section{B. Transient Response}

When the mass-spring system is subjected to the acceleration $a(t)$ in the sensing direction, the motion of the seismic mass can be expressed by:

$$
m \ddot{x}+c \dot{x}+k x=m a(t)
$$

where $k$ is the effective stiffness of the system, $x$ represents the relative displacement, $c$ is the damping coefficient and, $m$ is the effective mass of the proof mass. In the real world application environment, the input shock $a(t)$ is usually a half-sinusoidal wave with amplitude $a_{0}$ and pulse width $t_{0}$, which is given by: 


$$
a(t)=\left\{\begin{array}{ll}
a_{0} \cdot \sin \left(\frac{\pi t}{t_{0}}\right) & 0 \leq t \leq t_{0} \\
0 & t>t_{0}
\end{array}\right\}
$$

To simplify the analysis, we drop the damping term reducing Eq. (1) to

$$
m \ddot{x}+k x=m a(t)
$$

By solving the differential equation (3), the transient response $x(t)$ of the undamped system is given by [35]:

$$
x(t)=\frac{a_{0}}{(k / m)-\left(\pi / t_{0}\right)^{2}}\left[\sin \frac{\pi}{t_{0}} t-\frac{\pi}{\sqrt{k / m} t_{0}} \sin \sqrt{\frac{k}{m}} t\right]
$$

The derivative of Eq. (4) is also a function of the time $t$; from which the extreme points can be obtained. Then we can get the maximum value $x_{\max }$. When $x_{\max }$ arrives at the distance $x_{0}$ between two electrodes, the switch is activated, forming an external electrical circuit. By solving Eq. (4), the threshold acceleration $a_{t h}$ which can activate the micro-switch can be obtained. The threshold acceleration is then given by

$$
a_{t h}=x_{0} \frac{k / m-\left(\pi / t_{0}\right)^{2}}{\sin \frac{2 \pi}{1+\sqrt{k / m}\left(t_{0} / \pi\right)}-\frac{\pi / t_{0}}{\sqrt{k / m}} \sin \frac{2 \pi \sqrt{k / m}}{\pi / t_{0}+\sqrt{k / m}}}
$$

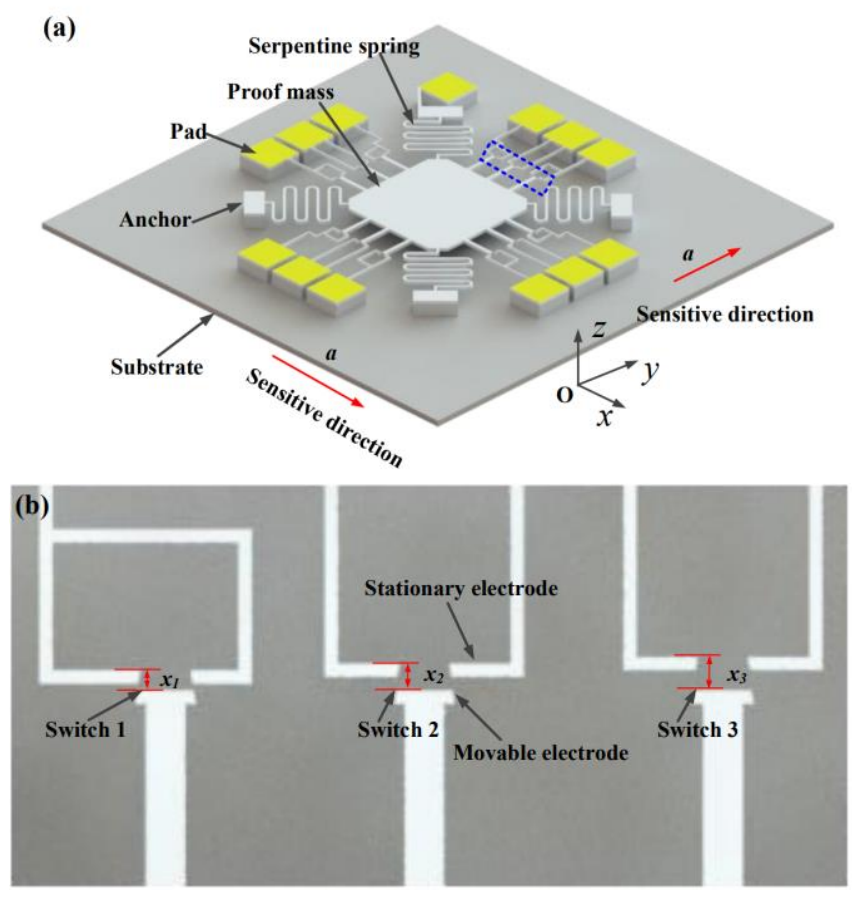

Fig. 1. (a) Schematic diagram of the proposed inertial microswitch with three threshold levels; (b) close-ups of the gaps $x_{1}, x_{2}, x_{3}$ between two electrodes in switch 1 , switch 2 , and switch 3

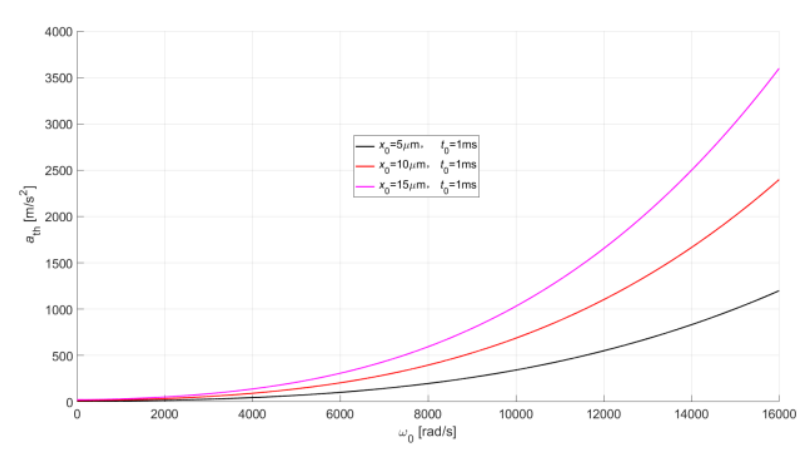

Fig.2 The analytically predicted threshold acceleration $a_{t h}$ versus natural frequency $\omega_{0}$.

Using Eq. (5), Fig. 2 shows the variation of the threshold accelerations $a_{t h}$ with the natural frequency $\omega_{0}=\sqrt{k / m}$ for three values of the targeted gap displacement $x_{0}$ between the two electrodes. It indicates that the threshold acceleration increases with $\omega_{0}$ and $x_{0}$. In the designed structure, the different gaps $x_{0}$ result in different threshold accelerations $a_{t h}$, so it can detect multiple threshold events over a wide operating range.

\section{Working Principle}

Fig.3 shows a flowchart for performing the digital classification in the 3-bit accelerometer of this work. "ON", "OFF" state in the digital acceleration output represents the logic output "1", "0" for each switch, respectively. The acceleration thresholds in switch 1, switch 2, and switch 3 are $a_{t h l}, a_{t h 2}$, and $a_{t h 3}$. If switch 1 does not make a contact when the device is subjected to an acceleration, it indicates that the acceleration is smaller than the first acceleration threshold $a_{t h l}$. In this case, all the switches are OFF. Hence, the digital acceleration output is " 000 " and the applied acceleration belongs to the range of $a<a_{t h l}$. If switch 1 closes alone, the applied acceleration is above or equal $a_{t h l}$. Just then, switch 2 and switch 3 are still "OFF", so the applied acceleration is below the second acceleration threshold $a_{t h 2}$. Correspondingly, the digital acceleration output is " 100 " and the acceleration must be between $a_{t h l}$ and $a_{t h 2}$. When switch 3 does not make a contact and both switch 1 and switch 2 are still "ON", it indicates that the applied acceleration exceeds the second acceleration threshold $a_{t h 2}$ but smaller than the third acceleration threshold $a_{t h 3}$. Hence, the digital acceleration output is "110". If the three switches are activated, it indicates that the digital acceleration output is " 111 " and the acceleration is above or equal $a_{t h 3}$. Table II shows the mapping of the digital acceleration output of the 3-bit inertial switch with three acceleration thresholds. The similar concept and principle are also applied to a higher number of bits in order to realize multiple thresholds inertial switch with higher resolutions, e.g. 10-bit and so on. 
TABLE II

THE SWITCH STATE AND ACCELERATION DIGITAL OUTPUT TO THE RANGE OF THE APPLIED ACCELERATION

\begin{tabular}{ccccc}
\hline Switch & Switch & Switch & $\begin{array}{c}\text { Acceleration Digital } \\
\text { Output }\end{array}$ & Acceleration Range \\
1 State & 2 State & 3 State & 000 & $a<a_{t h l}$ \\
\hline OFF & OFF & OFF & 100 & $a_{t h l} \leq a<a_{t h 2}$ \\
ON & OFF & OFF & 110 & $a_{t h 2} \leq a<a_{t h 3}$ \\
ON & ON & OFF & 111 & $a \geq a_{t h 3}$ \\
ON & ON & ON & 11 & \\
\hline
\end{tabular}

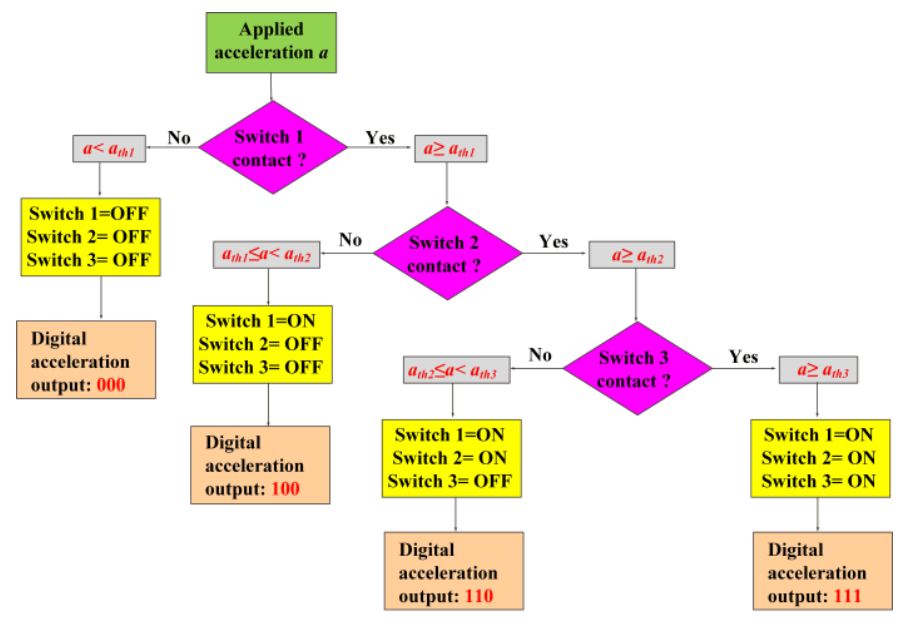

Fig. 3. Flowchart showing the algorithm of the digital shock/acceleration sensor with three threshold values.

\section{SIMULATION}

The microswitch model was built using the finite-element (FE) software ANSYS, Fig. 4. The model was used to simulate the dynamic contact process [36]. Transient analysis has been introduced to simulate the dynamic response of the inertial switch and evaluate its single-axial sensitivity. The solver is based on the large displacement transient. The element types of SOLID 186, TARGE170, and CONTA174 are used, and the model is meshed by the SWEEP model. The lateral surfaces between the stationary electrode and the movable electrode are defined as the contact pairs. The end sections of the fixed electrodes and the four suspended serpentine springs are constrained to zero in all degrees of freedom $(\mathrm{DOF}=0)$. The main structural material is silicon. The properties of silicon are as follows: Young's modulus is $130 \mathrm{GPa}$, Poisson's ratio is 0.23 , and density is $2.33 \mathrm{~g} \cdot \mathrm{cm}^{-3}$.

\section{A. Simulation of Dynamic Response}

The gap $x_{1}, x_{2}, x_{3}$ between the fixed electrode and the movable electrode 1,2 , and 3 are set to $5 \mu \mathrm{m}, 10 \mu \mathrm{m}$, and $15 \mu \mathrm{m}$, respectively. The simulated shock duration is set to $0.56 \mathrm{~ms}$, $0.38 \mathrm{~ms}, 0.36 \mathrm{~ms}$ based on the experimental shock duration in Table. IV. As shown in Fig. 5 and Table III, the simulated 1st, 2nd, and 3rd threshold accelerations are 1197g, 2186g, and $3314 \mathrm{~g}$, respectively.

TABLE III

THE SIMULATED THRESHOLD LEVELS OF THE INERTIAL SWITCH

\begin{tabular}{ccc}
\hline & The peak acceleration $(\mathrm{g})$ & $\begin{array}{c}\text { The pulse duration } \\
(\mathrm{ms})\end{array}$ \\
\hline The 1st threshold level & 1197 & 0.56 \\
The 2nd threshold level & 2186 & 0.38 \\
The 3rd threshold level & 3314 & 0.36 \\
\hline
\end{tabular}

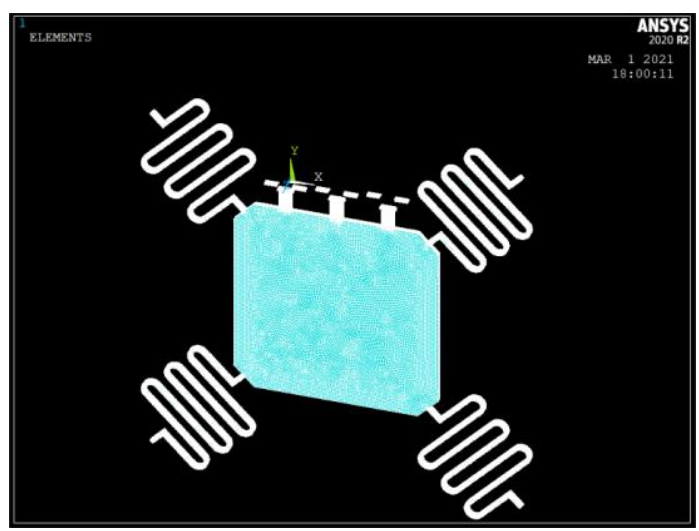

Fig. 4. The ANSYS finite element model of the inertial switch with three threshold levels for the dynamic contact process.

(a)

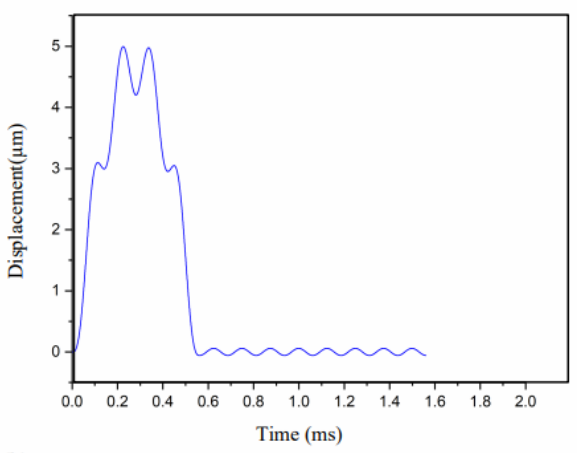

(b)

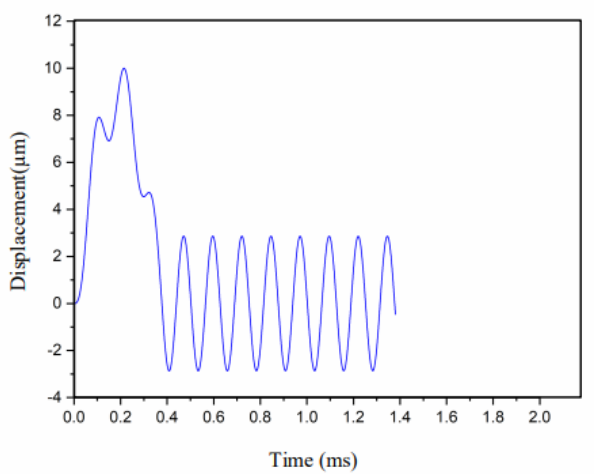

(c)

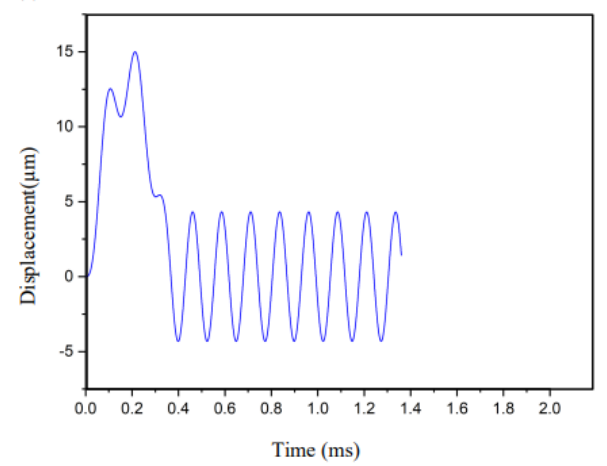

Fig. 5. The simulated dynamic response of the proof mass showing (a) the first threshold level with the peak acceleration of $1197 \mathrm{~g}$ and duration of $0.56 \mathrm{~ms}$, (b) the second threshold level with the peak acceleration of $2186 \mathrm{~g}$ and duration of $0.38 \mathrm{~ms}$, (c) the third threshold level with the peak acceleration of $3314 \mathrm{~g}$ and duration of $0.36 \mathrm{~ms}$. 


\section{B. Modal Analysis}

Modal analysis of the device (proof mass and suspended springs) is conducted by the finite element software COMSOL. Fig. 6 shows that the vibration frequencies of the first four modes are $5323 \mathrm{~Hz}, 7208 \mathrm{~Hz}, 7212 \mathrm{~Hz}$, and $11768 \mathrm{~Hz}$, respectively. It indicates that the first mode (Fig. 6a) moves parallels to the vertical direction (z-direction). The second mode and the third mode (Fig. 6b and Fig. 6c) move in the horizontal direction ( $x$-direction and $y$-direction). The fourth mode (Fig. 6d) swings up and down along the diagonal line of the proof mass. In the designed planar inertial switch, the $x$ and $y$ directions (in-plane motions) are equivalent. Here, only $y$ direction is discussed as the sensitive direction. The natural period of the third mode $T_{n a t}$ (the inverse of frequency) is $0.138 \mathrm{~ms}$.

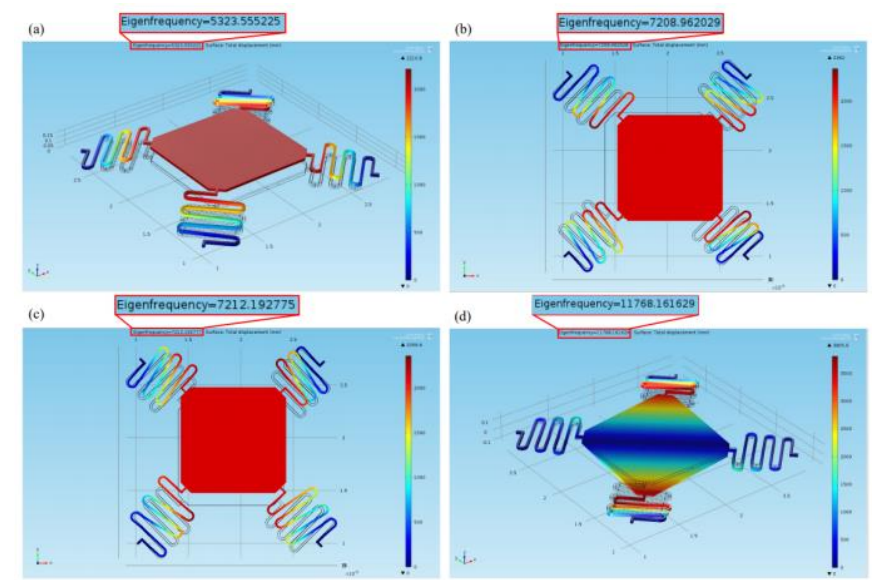

Fig. 6. The first four mode shapes of the device. (a) First mode. (b) Second mode. (c) Third mode. (d) Fourth mode.

\section{Quasi-Static and Dynamic Loads}

Fig.7 shows the dynamic response amplification of the response, dynamic amplitude $A_{d y n}$ normalized to that of an equivalent static load, when changing $T / T_{n a t}$, where $T$ and $T_{n a t}$ are the duration of the half-sine shock pulse and the natural period of the spring-mass system, respectively [37]. When the ratio $T / T_{\text {nat }}$ approximately varies from 0.5 to 4.0 , one can see that the response experiences large amplification. This corresponds to dynamic loading cases. The peak of the response occurs when $T / T_{\text {nat }} \approx 0.8$, at which the response due to shock peaks at $A_{d y n} / A_{\text {stat }}=1.76$. When the ratio $T / T_{\text {nat }}$ is greater than 4.0, it represents the quasi-static regime. Notice here that $A_{\text {dyn }} / A_{\text {stat }}$ gets closer to unity as the ratio $T / T_{\text {nat }}$ gets larger.

Generally speaking, an input shock pulse can be assumed as a quasi-static load when the period of the input shock is more than about 5 times the natural period of the structure. In this work, the natural period of the structure is $0.138 \mathrm{~ms}$. Fig. 8 shows the simulated dynamic response of the proof mass with different periods of shock load. For a shock load of $T=0.84 \mathrm{~ms}$, $T / T_{\text {nat }}=6.08$, which belongs to the quasi-static regime. The maximum displacement is $2.88 \mu \mathrm{m}$ as shown in Fig. 8(a). If the duration $T$ becomes $0.138 \mathrm{~ms}$, then $T / T_{\text {nat }} \approx 1.0$, indicating dynamic regime, and the maximum displacement is $4.58 \mu \mathrm{m}$ as shown in Fig. 8(b). Here the amplitude experiences large amplification. Also, it indicates that a smaller threshold level is required to make the proof mass travel the gap $x_{l}$ for the case of shock duration $T=0.138 \mathrm{~ms}$ (dynamic load) compared to the shock duration of $T=0.84 \mathrm{~ms}$ (quasi-static load).

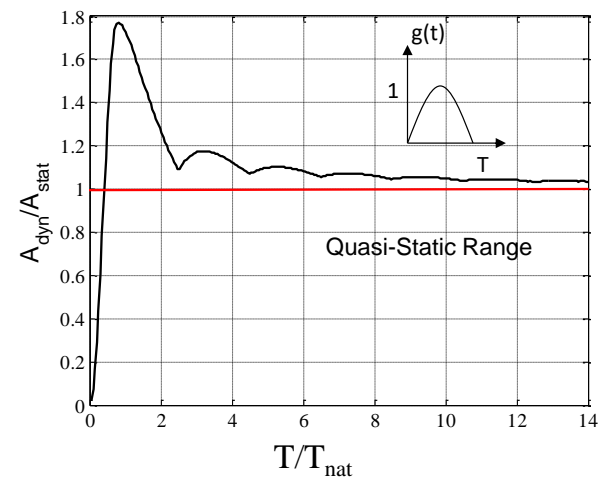

Fig. 7. A shock-response spectrum (SRS) of a spring-mass system under a half-sine shock pulse.

(a)

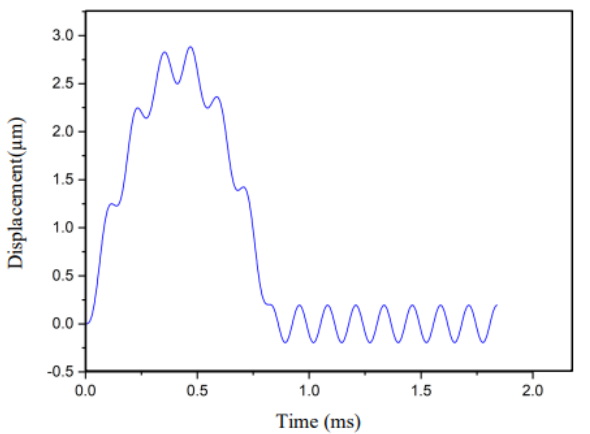

(b)

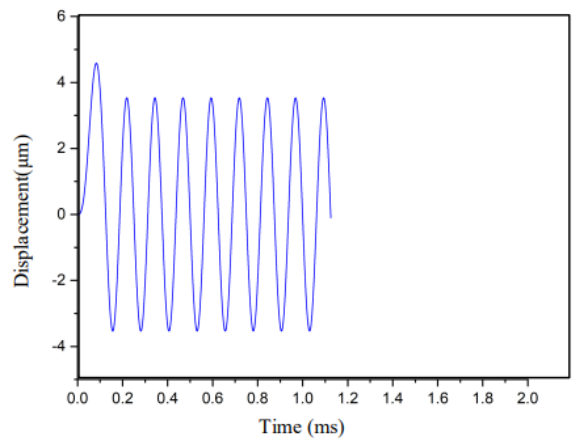

Fig. 8. Simulated dynamic response of the inertial switch under a shock pulse of amplitude $678 \mathrm{~g}$ and (a) quasi-static case of $\mathrm{T}=0.84 \mathrm{~ms}$, (b) dynamic loading case of $\mathrm{T}=0.138 \mathrm{~ms}$.

\section{Simulation of Axial Disturbance Performance}

The single-axis sensitivity of the inertial switch is a critical performance parameter in the inertial switch. Fig.9 shows simulated displacement of the inertial switch in the sensing-axis $y$-direction and the off-axis sensing $x$-direction when $1197 \mathrm{~g}$ shock acceleration is applied to the device in $y$-direction. The maximum displacement of the inertial switch in the $x$-direction is smaller than $0.4 \mu \mathrm{m}$ while the maximum displacement of the inertial switch in the sensitive direction is $5 \mu \mathrm{m}$. One can conclude that the symmetrical distribution of the designed structure can effectively lower the off-axis sensitivity and improve the single-axis sensitivity of the inertial switch. 


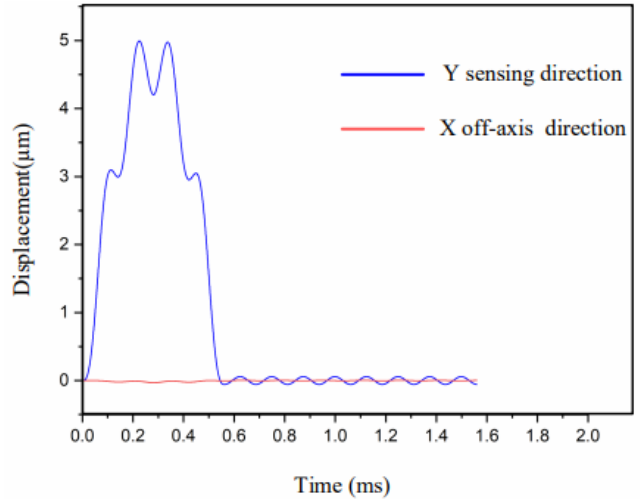

Fig. 9. Simulated dynamic response of the inertial switch showing the amplitude in the sensing-axis $y$-direction and the off-axis sensing $x$-direction.

\section{FABRICATION}

The multi-threshold inertial switches were fabricated by MEMSCAP based on Silicon-On-Insulator Multi-User MEMS process (SOIMUMPs). SOIMUMPs are designed for general-purpose micromachining of Silicon-on-Insulator (SOI) structures and are used to fabricate in-plane MEMS devices [38]. Fig. 10(a) shows a top view of one of the fabricated devices. Fig. 10(b) shows a close-up of the overlap and contact area of gaps $x_{1}, x_{2}, x_{3}$ between the movable electrode and the stationary electrode 1,2 , and 3 with values $5 \mu \mathrm{m}, 10 \mu \mathrm{m}$, and $15 \mu \mathrm{m}$, respectively.

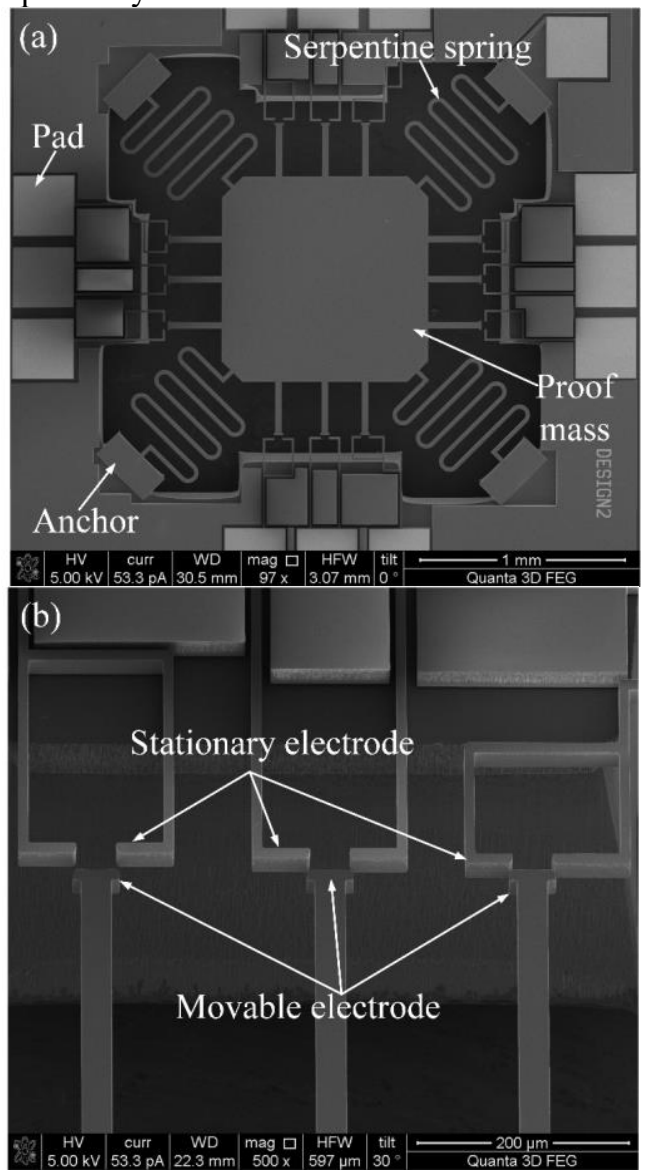

Fig. 10. (a) SEM image of the multi-threshold switch prototype. (b) An enlarged view of the different gaps between the movable electrode and the stationary electrode 1,2 , and 3 .

\section{EXPERIMENT}

\section{A. Setup}

The fabricated devices are tested by a drop table test system by Lansmont. Fig. 11 shows the shock table experimental setup and its schematic configuration. A reference accelerometer is used for the calibration to test the acceleration of the tested devices. An oscilloscope (Agilent 6000 MSO6034A) is used to capture the trigger signal from the tested inertial switches. The tested prototypes are fixed on the side face of a 3-D printed fixture mounted on the shock table, as shown in Fig. 11(a). Fig. 11(b) shows the image of the tested devices and shock table. Fig. 9(c) displays a schematic diagram for the test circuit showing the connection among the power source, tested switch, and multi-channel oscilloscope. In the present experiment, the tested switch was connected to a power source $(10 \mathrm{~V})$ with three divider resistances $\left(\mathrm{R}_{1}, \mathrm{R}_{2}, \mathrm{R}_{3}\right)$ of $300 \Omega$. When the acceleration amplitude exceeds a threshold value, the trigger signal of switch 1 , switch 2 , and switch 3 can be simultaneously captured by the multi-channel oscilloscope.

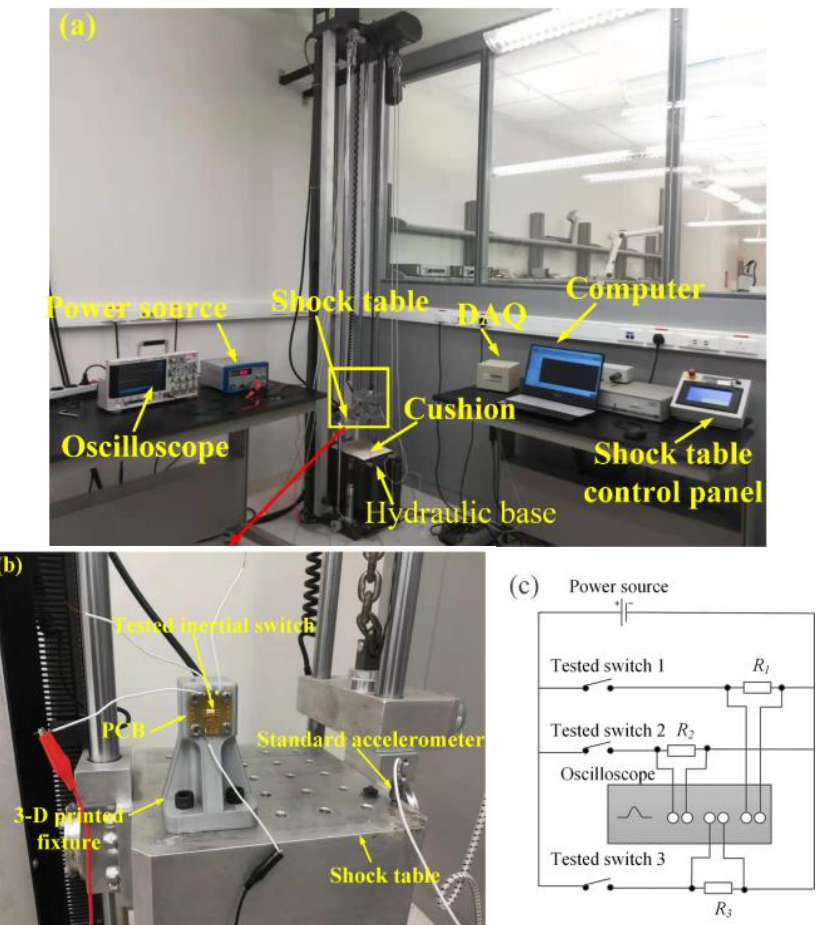

Fig. 11. (a) A picture of the drop table test system used to test the fabricated prototypes. (b) Close-ups of the shock table and the tested prototypes. (c) The corresponding schematic configuration of the test circuit.

In order to generate a shock, the hoist lifts the shock table to a pre-determined height. Then the shock table is freely released allowing it to accelerate until it abruptly hits the hydraulic base at the bottom generating the shock impact on the tested device. The magnitude of the shock impact increases with the pre-determined height. The shock duration depends on the stiffness of the cushioning sponge between the shock table and the hydraulic base. The shock duration increases by adding more cushioning sheets to the hydraulic base. Generally, the drop table system generates a half-sine shock pulse of duration ranges from $0.5 \mathrm{~ms}$ to $4 \mathrm{~ms}$. When the shock table was released freely from the pre-set height of $14 \mathrm{~cm}$, the tested device 
experienced a shock pulse of magnitude $787 \mathrm{~g}$ and duration 0.56ms, as shown in Fig. 12.

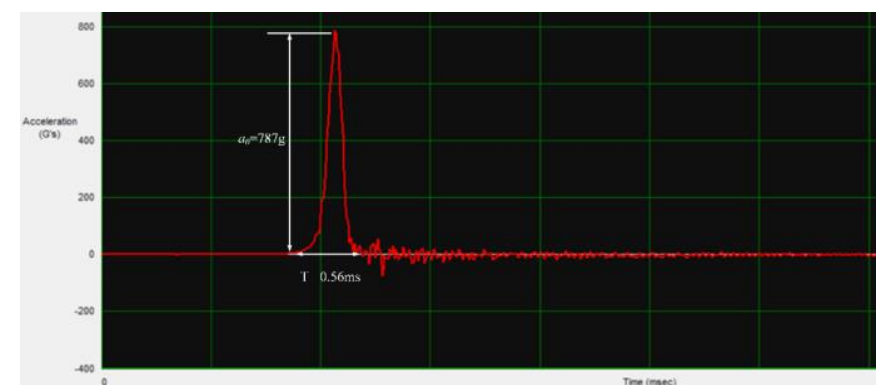

Fig. 12. Example of a shock pulse generated from a shock table system with amplitude of $787 \mathrm{~g}$ and duration $0.56 \mathrm{~ms}$.

\section{B. Test Results}

When the device is subjected to an acceleration at or above the threshold level, the multi-channel oscilloscope captures the switching signal. In this work, $x$ and $y$ directions (in-plane motions) are equivalent. Here, for brevity, only $+y$ direction is discussed as the sensitive direction. The multi-threshold inertial switch in $+y$ axis is made up of three switches. The test results are presented in Fig.13. Three signals generated from the multichannel oscilloscope are shown: the yellow signal represents the contact signal in switch 1 ; the contact triggering in switch 2 is represented by the green signal; and the blue signal is for the trigger of switch 3 . Firstly we test the 1 st threshold acceleration. In order to achieve the 1 st threshold level, the preset height $H$ is gradually increased until the switch trigger signal is observed. As shown in Fig. 13(a), none of the three signals can be observed under the shock impact with the amplitude of $809 \mathrm{~g}$ and shock duration $0.56 \mathrm{~ms}$. It indicates that the acceleration with the amplitude of $809 \mathrm{~g}$ is less than the first threshold value. Fig. 13(b) shows that the yellow trigger signal starts to appear when the magnitude of the shock pulse increases to $865 \mathrm{~g}$ with a duration of $0.56 \mathrm{~ms}$. This acceleration defines the first threshold acceleration of switch 1 . Fig. 13(c) shows the response under $1100 \mathrm{~g}$ and pulse duration $0.56 \mathrm{~ms}$, which is similar to Fig. 13(b). Only the yellow trigger can be observed, however, the bouncing behavior can be observed and the contact time is extended. When the device is subjected to an acceleration of $1699 \mathrm{~g}$, the green trigger signal appears and we still can observe the yellow signal as shown in Fig. 13(d). It indicates that the acceleration of $1699 \mathrm{~g}$ is the second threshold level for switch 2. As is illustrated in Fig. $13(\mathrm{e})$, there is no blue trigger signal under 1959g. It indicates that switch 1 and switch 2 are in the ON state, but switch 3 is in OFF state. A blue trigger signal begins to appear under $2399 \mathrm{~g}$ with a duration of $0.36 \mathrm{~ms}$ as shown in Fig. 13(f). So the threshold level in switch 3 is $2399 \mathrm{~g}$. With the increase of acceleration, the three trigger signals can be observed under $2943 \mathrm{~g}$ and shock duration $0.34 \mathrm{~ms}$ as shown in Fig. 13(g). The threshold accelerations of each switch are shown in Table IV. Comparing Table. III to Table. IV, the tested threshold levels are smaller than the simulated ones. Potential reasons for the discrepancy can be the fact that the wave of tested acceleration deviated from the ideal half-sine wave of simulated one and fabrication imperfection (non-uniformity of width during DRIE process; consequently decreasing the spring stiffness of the structure).
TABLE IV

THE MEASURED THRESHOLD LEVELS OF THE MULTI-THRESHOLD INERTIAL SWITCH

\begin{tabular}{|c|c|c|}
\hline & $\begin{array}{l}\text { The peak acceleration } \\
(\mathrm{g})\end{array}$ & $\begin{array}{l}\text { The pulse duration } \\
\text { (ms) }\end{array}$ \\
\hline $\begin{array}{l}\text { 1st threshold } \\
\text { acceleration }\end{array}$ & 865 & 0.56 \\
\hline $\begin{array}{l}\text { 2nd threshold } \\
\text { acceleration }\end{array}$ & 1699 & 0.38 \\
\hline $\begin{array}{l}\text { 3rd threshold } \\
\text { acceleration }\end{array}$ & 2399 & 0.36 \\
\hline
\end{tabular}

\section{Digital Classification for Inertial Switches with Three Threshold Levels}

This work presents micro switches with three acceleration thresholds, which can perform quantitative acceleration measurements. Such devices can be viewed as a 3-bit digital accelerometer. Fig. 14 shows a flowchart for performing the digital search in a 3-bit accelerometer. "ON", "OFF" state in the digital acceleration output represents the logic output " 1 ", " 0 " for each switch, respectively. The details of Fig. 14 are as follows:

(1) If no signal is observed when the acceleration applies to the device, it indicates that all three switches are not activated. In this case, the applied acceleration is below the 1st threshold acceleration and the digital acceleration output is " 000 ". Therefore the applied acceleration belongs to the range of $0-865 \mathrm{~g}$.

(2) If the yellow trigger signal appears, this indicates that switch 1 is activated and the digital acceleration output is " 1 ". If, in addition, there are no green and blue signals, it indicates that both switch 2 and switch 3 are OFF. In this case, both the second digit and the third digit in the digital acceleration output are " $0 "$ ". So the digital acceleration output is " 100 ". Subsequently, the acceleration applied to the device ranges from $865 \mathrm{~g}$ to $1699 \mathrm{~g}$.

(3) If both yellow and green signals are only detected, it indicates that both switch 1 and switch 2 are ON and that switch 3 is OFF. Hence, the digital acceleration output is " 110 ". So the applied acceleration would be between $1699 \mathrm{~g}$ and $2399 \mathrm{~g}$.

(4) If three color signals are observed, the three switches are activated indicating that the acceleration level is above or equal to $2399 \mathrm{~g}$ and the digital acceleration output is " 111 ".

In summary, the test results demonstrate that the proposed switch can be capable of detecting a shock range from 800 to $2600 \mathrm{~g}$ with three threshold levels. When mobile and handheld electronic devices drop, the shock impact pulse normally approaches $1500 \mathrm{~g}$. It easily leads to the failure of solder joints inside handheld electronic devices [39]. The proposed switch can provide quantitative acceleration measurements in order to judge whether the joints fail or not. Table $\mathrm{V}$ shows the mapping of the digital acceleration output of the 3-bit inertial switch with three acceleration thresholds. 

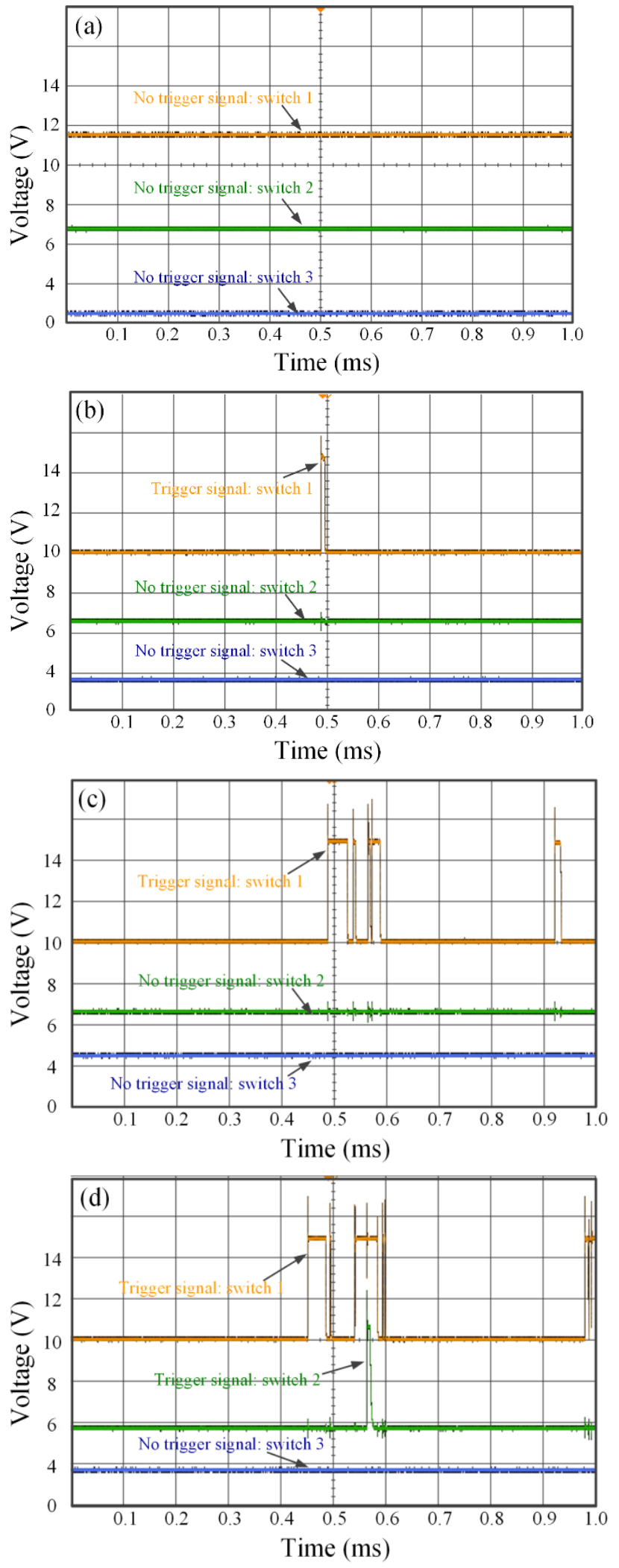
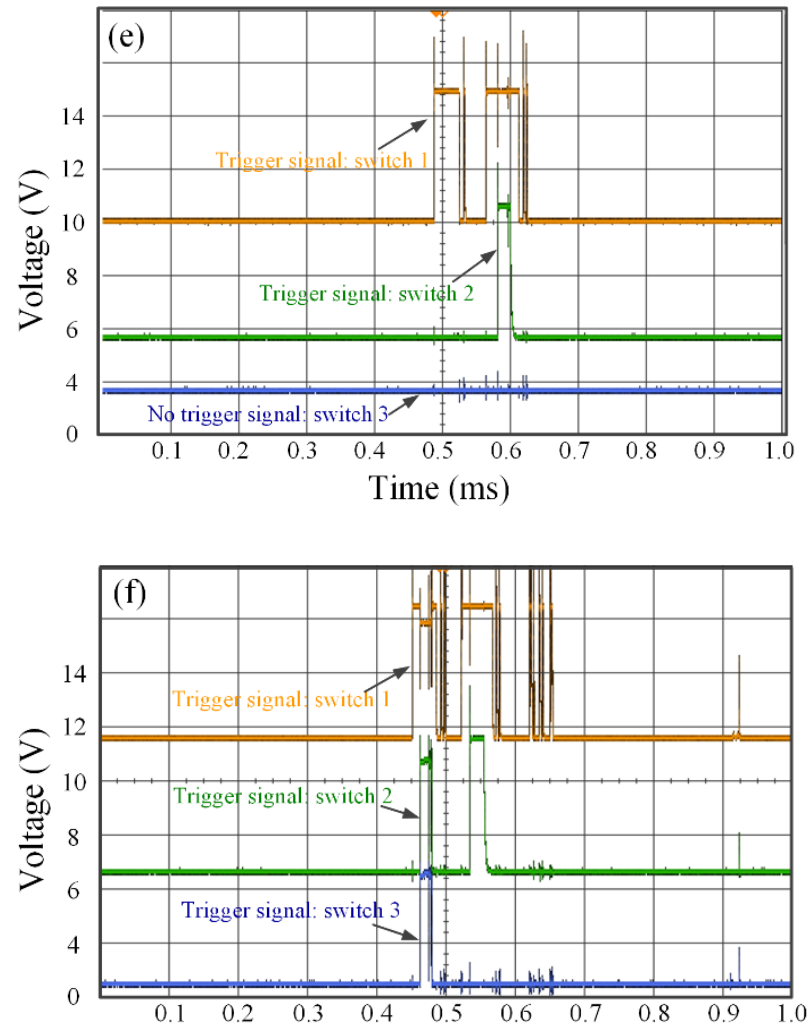

Time (ms)

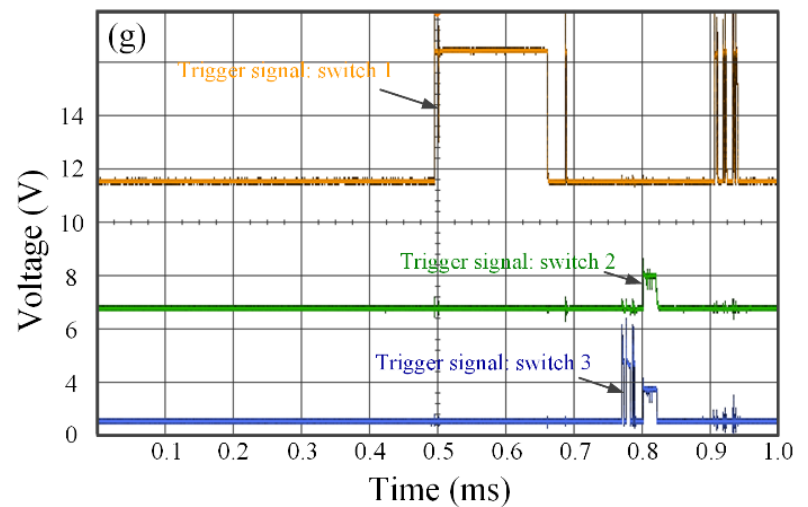

Fig. 13. Test results of the fabricated device. (a) The switch is in OFF state under the acceleration with the amplitude $809 \mathrm{~g}$ and the pulse duration $0.56 \mathrm{~ms}$. (b) One switch is $\mathrm{ON}$, as seen from the yellow signal, under an acceleration of $865 \mathrm{~g}$ pulse with a duration of $0.56 \mathrm{~ms}$. So the amplitude of threshold acceleration is $865 \mathrm{~g}$ in switch 1. (c) There is a yellow trigger signal when the switch is subjected to $1100 \mathrm{~g}$ pulse of duration $0.56 \mathrm{~ms}$, however, the bouncing behavior can be observed and the contact time is extended. (d) The second switch is triggered, as seen from the green signal, under $1699 \mathrm{~g}$ pulse of duration $0.38 \mathrm{~ms}$. The threshold level in switch 2 is $1699 \mathrm{~g}$. (e) There is no blue signal under $1959 \mathrm{~g}$ pulse of duration $0.36 \mathrm{~ms}$. It indicates that switch 1 and switch 2 are triggered while switch 3 is still in OFF state. (f) Switch 3 is now triggered, as seen from the blue trigger under $2399 \mathrm{~g}$ pulse and duration $0.36 \mathrm{~ms}$. So the threshold level of switch 3 is $2399 \mathrm{~g}$. (g) The three trigger signals can be observed under the acceleration pulse of amplitude $2943 \mathrm{~g}$ and duration $0.34 \mathrm{~ms}$. 


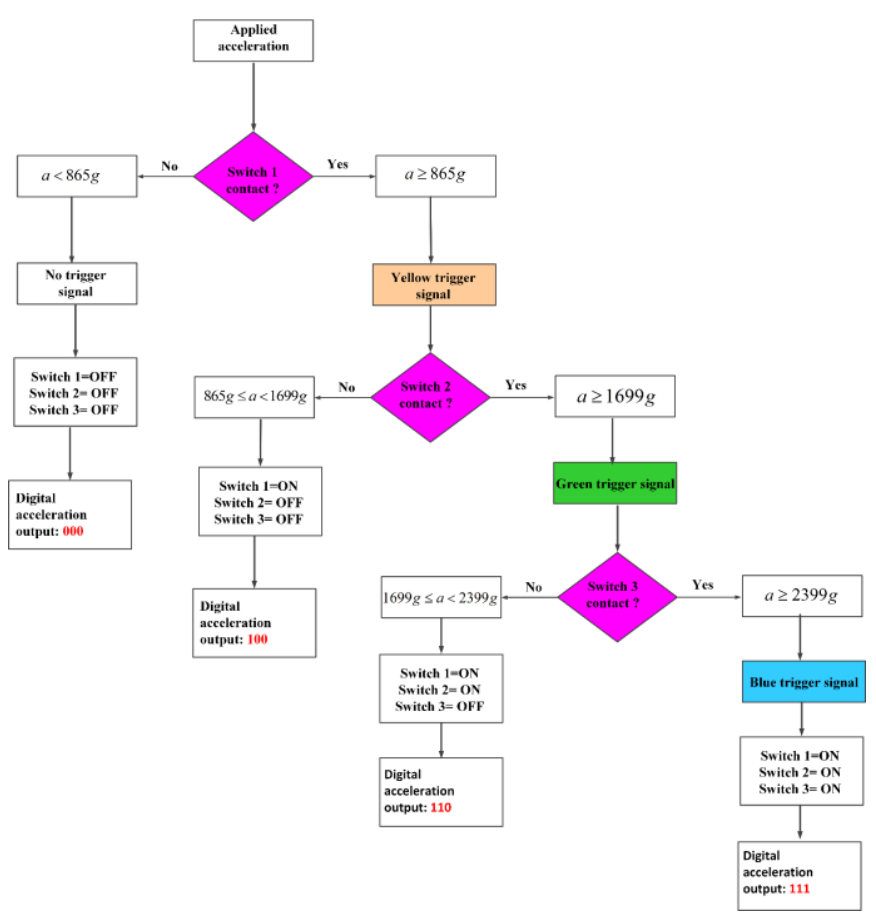

Fig.14. Flowchart showing the algorithm of the digital shock/acceleration sensor with three threshold values.

\section{Axial Disturbance Performance}

When the device is subjected to an acceleration at or above the threshold value, two contact signals from $x$ and $y$ directions can be both captured. The performance of axial disturbance is evaluated by measurements. In the designed planar multi-threshold inertial switch, $x$ and $y$ directions (in-plane motions) are equivalent. When $y$ direction is considered as the sensitive direction, then $x$ direction becomes the off-axis sensitive direction as shown in Fig. 1. Next, the yellow signal represents the trigger signal in the sensing $y$-direction; while the red signal refers to trigger signal in the off-axis $x$-direction.

When the device was subjected to a half-sine shock of $1209 \mathrm{~g}$ in the sensing $y$-direction, the switch output signal in the sensing direction can be observed as shown in Fig. 15(a). No off-axis signal is observed. The same results are observed when the acceleration increases to $2688 \mathrm{~g}$, Fig. 13(b). So the contact in off-axis $x$-direction is avoided when the acceleration in the sensing $y$-direction is applied to the device. It indicates that the crosstalk between the $x$ and $y$ directions is restrained. These tested results also demonstrate that the axial disturbance is low. The designed symmetrical structure plays an important role in lowering off-axis sensitivity and improving single-axial sensitivity.

TABLE $V$

THE ACCELERATION DIGITAL OUTPUT TO THE RANGE OF THE MEASURED ACCELERATION

\begin{tabular}{cccl}
\hline Switch 1 & Switch 2 & Switch 3 & $\begin{array}{l}\text { Acceleration } \\
\text { range }\end{array}$ \\
\hline 0 & 0 & 0 & $a<865$ \\
1 & 0 & 0 & $865 \leq a<1699$ \\
1 & 1 & 0 & $1699 \leq a<2399$ \\
1 & 1 & 1 & $a \geq 2399$ \\
\hline
\end{tabular}
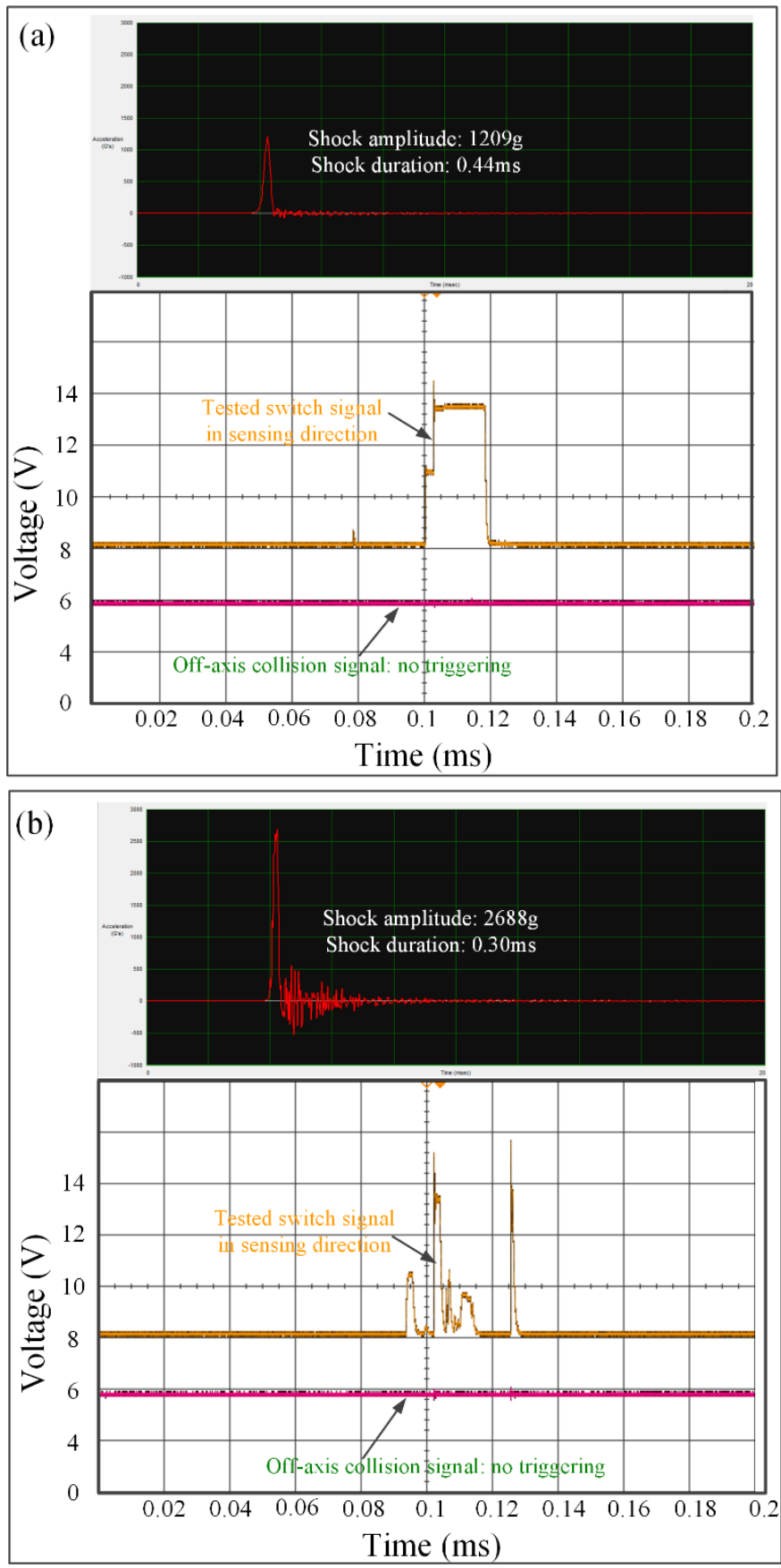

Fig. 15. Measured output signals of the inertial switch in the sensing $y$-direction and the off-axis $x$-direction when subjected to the shock pulse (a) of amplitude $1209 \mathrm{~g}$ and (b) of amplitude $2688 \mathrm{~g}$ in the sensing $y$-direction.

\section{CONCLUSION}

A laterally-driven multi-threshold inertial switch based on SOIMUMPs has been successfully designed, simulated, fabricated, and tested. It was demonstrated that multi-threshold inertial switches can be exploited to realize higher resolution digital quantitative acceleration measurements. A laterally-driven multi-threshold inertial switch with a 4 digital output was successfully demonstrated. It can perform quantitative acceleration measurements and sense an acceleration range of $800 \mathrm{~g}-2600 \mathrm{~g}$. The designed structure can avoid the crosstalk between different sensitive directions. The 
tested results are in good agreement with the simulated ones. Future research can be focused on expanding the capability of the device to implement 4-bit, 5-bit, or even higher resolution inertial switches.

\section{ACKNOWLEDGMENTS}

This publication is based upon work supported by King Abdullah University of Science and Technology (KAUST). I would dedicate my appreciations to Ph.D student Lvjun Wang for his beneficial discussion and continuous support, especially taking the SEM photograph.

\section{REFERENCES}

[1] J.C. Kuo, P.H. Kuo, Y.T. Lai, C.W. Ma, S.S Lu, Y.J.J. Yang, “A passive inertial switch using MWCNT-hydrogel composite with wireless interrogation capability," J.Micromech. Microeng., vol. 22, no. 3, pp. 646-654, Jan. 2013.

[2] C.W. Ma, P.C. Huang, J.C Kuo, W.C. Kuo, Y.J. Yang, “A novel inertial switch with an adjustable acceleration threshold using an MEMS digital-to-analog converter," Microelectron Eng., vol. 110, pp. 374-380, Oct. 2013.

[3] H. Cai, Yang, G. Ding, \& H. Wang, "Development of a novel MEMS inertial switch with a compliant stationary electrode," IEEE Sens. J., vol. 9, no. 7, pp. 801-808, Jun. 2009

[4] L.J. Currano, M. Yu, B. Balachandran, "Latching in a MEMS shock sensor: Modeling and experiments," Sens. Actuators A, vol. 159, no. 1, pp. 41-50, Apr. 2010.

[5] Q. Xu, Z. Yang, Y. Sun, L. Lai, Z. Jin, G. Ding, X. Zhao, J. Yao, J. Wang, "Shock-resistibility of mems-based inertial microswitch under reverse directional ultra-high g acceleration for IoT applications," Sci. Rep., vol. 7, no. 1, pp. 1-12, Mar. 2017.

[6] S. Michaelis, H.J. Timme, M. Wycisk, J. Binder, "Additive electroplating technology as a post-CMOS process for the production of MEMS acceleration-threshold switches for transportation applications," J.Micromech. Microeng, vol. 10, no. 2, pp. 120-123, Jun. 2000.

[7] T. Matsunaga, M. Esashi, "Acceleration switch with extended holding time using squeeze film effect for side airbag systems," Sens. Actuators A, vol. 100, no. 1, pp. 10-17, Aug. 2002.

[8] M. Wycisk, T. Tönnesen, J. Binder, S. Michaelis, H.J. Timme, "Low-cost post-CMOS integration of electroplated microstructures for inertial sensing," Sens. Actuators A, vol. 83, no. 1-3, pp. 93-100, May 2000.

[9] W. Chen, Y. Wang, Y. Zhang, P. Cheng, Y. Wang, G. Ding, Z. Yang, "Fabrication of a novel contact-enhanced horizontal sensitive inertial micro-switch with electroplating nickel," Microelectron Eng., vol. 127 pp. 21-27, Sep. 2014.

[10] W. Tian, Z. Chen, "Analysis of bistable inductive micro-switch based on surface micro size effect," Appl. Surf. Sci., vol. 334, pp. 32-39, Apr. 2015.

[11] Q. Xu, B. Sun, Y. Li, X. Xiang, L. Lai, J. Li, G. Ding, X. Zhao, Z. Yang, "Design and characterization of an inertial microswitch with synchronous follow-up flexible compliant electrodes capable of extending contact duration," Sens. Actuators A, vol. 270, pp. 34-45, Feb. 2018.

[12] Q. Xu, Z.Q. Yang, B. Fu, Y.P. Bao, H. Wu, Y.N. Sun, M.Y. Zhao, J. Li, G.F. Ding, X. L. Zhao, "Design and Optimization of a stationary electrode in a vertically-driven mems inertial switch for extending contact duration," Sensors, vol. 17, no. 3, pp. 527-544, Mar. 2017.

[13] M.I. Younis, R. Miles, D. Jordy, "Investigation of the response of microstructures under the combined effect of mechanical shock and electrostatic forces," J.Micromech. Microeng., vol. 16, no. 11, pp. 2463-2474, Oct. 2006.

[14] M.I. Younis, F.M. Alsaleem, R. Miles, Q. Su, "Characterization of the performance of capacitive switches activated by mechanical shock,"
J.Micromech. Microeng., vol. 17, no. 7, pp. 1360-1370, Jun. 2007.

[15] X. Zhang, X. Xiang, Y. Wang, G. Ding, X. Xu, \& Z. Yang, "A Heterogeneous Integrated MEMS Inertial Switch With Compliant Cantilevers Fixed Electrode and Electrostatic Locking to Realize Stable On-State," J. Microelectromech Syst., vol. 28, no. 6, pp. 977-986, Sep. 2019.

[16] W. Chen, H. Wang, D. Kong, S. Sun, "The Elastic Contact and Stability Analysis of an Inertial Micro-Switch with a Spring Stationary Electrode," Sensors, vol. 18, no. 12 pp. 4238-4250, Dec. 2018.

[17] P.M. Zavracky, S. Majumder, N.E. McGruer, "Micromechanical switches fabricated using nickel surface micromachining," J Microelectromech. Syst., vol. 6, no. 1, pp. 3-9, Mar. 1997.

[18] H. Tai-Ran, MEMS \& microsystems: design and manufacture. Mechanical engineering series. McGraw-Hill, 2002.

[19] J. Zhao, J. Jia, H. Wang, \& W. Li, "A novel threshold accelerometer with postbuckling structures for airbag restraint systems," IEEE Sens. J., vol. 7, no. 8, pp. 1102-1109, Jun. 2007.

[20] H.M. Ouakad, M.I. Younis, F. Alsaleem, "Dynamic response of an electrostatically actuated microbeam to drop-table test," J.Micromech. Microeng., vol. 22, no. 9, pp. 095003, Jul. 2012.

[21] A. Ramini, M.I. Younis, Q.T. Su, "A low-g electrostatically actuated resonant switch," Smart Mater. Struct., vol. 22, no. 2, pp. 025006, Dec. 2012.

[22] Q. Xu, Z. Yang, B. Fu, J. Li, H. Wu, Q. Zhang, Y. Sun, G. Ding, X. Zhao, "A surface-micromachining-based inertial micro-switch with compliant cantilever beam as movable electrode for enduring high shock and prolonging contact time," Appl. Surf. Sci., vol. 387, pp. 569-580, Nov. 2016.

[23] Z. Yang, J. Shi, J. Yao, X. Zhang, G. Ding, \& X. Zhao, "A laterally driven MEMS inertial switch with double-layer suspended springs for improving single-axis sensitivity." IEEE. Trans. Compon. Packaging Manuf. Technol. vol. 8, no. 10, pp. 1845-1854, Aug. 2018.

[24] W. Chen, R. Wang, H. Wang, D. Kong, \& S. Sun, "The Analysis of the Influence of Threshold on the Dynamic Contact Process of a Fabricated Vertically Driven MEMS Inertial Switch," Micromachines, vol. 10, no. 11, pp.791, Nov. 2019.

[25] V. Kumar, X. Guo, R. Jafari, S. Pourkamali, "A tunable digitally operated MEMS accelerometer," Busan, Korea, IEEE SENSORS conference (pp. 1-4), Nov. 1, 2015.

[26] V. Kumar, R. Jafari, S. Pourkamali, "Ultra-low power digitally operated tunable MEMS accelerometer," IEEE Sens. J., vol. 16, no. 24, pp. 8715-8721, May 2016

[27] W. Chen, Z. Yang, Y. Wang, G. Ding, H. Wang, \& X. Zhao, "Fabrication and characterization of a low-g inertial microswitch with flexible contact point and limit-block constraints," IEEE ASME Trans. Mechatron. vol. 21, no. 2, pp. 963-972, Aug. 2015.

[28] W.D. Frobenius, S.A. Zeitman, M.H. White, D.D. O'Sullivan, R.G. Hamel, Microminiature ganged threshold accelerometers compatible with integrated circuit technology. IEEE Trans. on electron devices, 19(1), 37-40, 1972.

[29] L.J. Currano, C.R. Becker, D. Lunking, G.L. Smith, B. Isaacson, L. Thomas, "Triaxial inertial switch with multiple thresholds and resistive ladder readout," Sens. Actuators A, vol. 195, pp. 191-197, Jun. 2013.

[30] A. Selvakumar, N. Yazdi, K. Najafi, "A wide-range micromachined threshold accelerometer array and interface circuit," J.Micromech. Microeng., vol. 11, no. 2, pp. 118, Mar. 2001.

[31] R.R. Reddy, K. Komeda, Y. Okamoto, E. Lebrasseur, A. Higo, Y. Mita, "A zero-power sensing MEMS shock sensor with a latch-reset mechanism for multi-threshold events monitoring," Sens. Actuators A, vol. 295, pp. 1-10, Aug. 2019.

[32] G.Z. Guo, Z.C. Yang, L.T. Lin, Q.C. Zhao, H.T. Ding, X.S. Liu, G.Z. Yan, "Design, fabrication and characterization of a latching acceleration switch with multi-contacts independent to the proof-mass," Sens. Actuators A, vol. 166, no. 2, pp. 187-192, Apr. 2011.

[33] Y. Lee, S.M. Sim, H. Kim, Y.K. Kim, J.M. Kim, "Silicon MEMS acceleration switch with high reliability using hooked latch," Microelectron Eng., vol. 152, pp. 10-19, Feb. 2016.

[34] H. Kim, Y.H. Jang, Y.K. Kim, J.M. Kim, "MEMS acceleration switch with bi-directionally tunable threshold," Sens. Actuators A, vol. 208, pp. 120-129, 2014.

[35] H. Cai, Z. Yang, G. Ding, \& X. Zhao, "Fabrication of a MEMS inertia switch on quartz substrate and evaluation of its threshold acceleration," Microelectronics J, vol. 39, no. 9, pp. 1112-1119, 2008.

[36] ANSYS Inc.: www.ansys.com. 
[37] M.I. Younis, MEMS linear and nonlinear statics and dynamics. Springer Science \& Business Media, 2011,pp.407-409.

[38] A. Cowen, G. Hames, D. Monk, S. Wilcenski, \& B. Hardy, SOIMUMPs design handbook, MEMSCAP Inc, 2002-2011.

[39] J. Pan, M. Krist, A. Farris, N. Vickers, "drop impact dynamic response study of Jedec Jesd22-b111 test board", Honors Undergraduate Research Journal, vol. 2, no. 2, pp. 80-96, 2009.

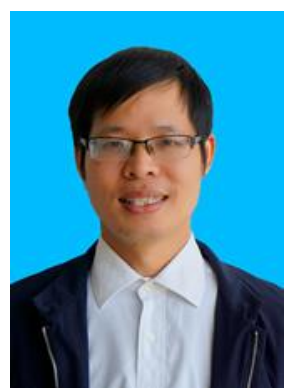

Qiu Xu received the B.Sc. degree from Jiangxi Normal University, Nanchang, China, in 2003. He received the M.Sc. degree from Shanghai Normal University, Shanghai, China, in 2007. $\mathrm{He}$ the Ph.D. degree in microelectronics and solid state electronics at the National Key Laboratory of Science and Technology on Micro/Nano Fabrication, Shanghai Jiao Tong University, Shanghai, China, in 2017. He is currently a postdoctoral fellow at King Abdullah University of Science and Technology, Saudi Arabia. His research interests include the design, simulation, and fabrication of MEMS/NEMS devices.

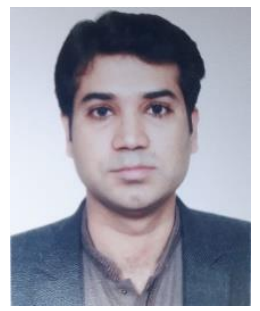

Dr. Fahimullah Khan received the BSc. degree in Electrical Engineering from University of Engineering and Technology, Peshawar, Pakistan in 2008 and MS in Electronic Engineering from Ghulam Ishaq Khan Institute of Science and Technology, Swabi, Pakistan in 2008. Afterwards, he obtained $\mathrm{PhD}$ in Micro-electronic Engineering from Griffith University, Gold Coast, Australia in Dec 2015. From the past few years, he was designated with various teaching and research positions. He is currently a Post-doc Fellow at King Abdullah University of Science and Technology. His research interests include micro/nanosystems, smart materials and structures, RF MEMS devices, and smart sensors.

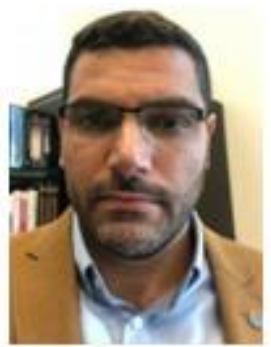

Mohammad I. Younis received a Ph.D. degree in engineering mechanics from Virginia Polytechnic Institute and State University in 2004. Since 2004, he has served as an assistant and then an associate professor of mechanical engineering at State University of New York at Binghamton. He is currently a Professor of Mechanical Engineering and the Director of the MEMS and NEMS Characterization and Motion Laboratory at King Abdullah University of Science and Technology, Saudi Arabia. Dr. Younis is a recipient of the SUNY Chancellor's Award for Excellence in Scholarship and Creative Activities in 2012, the National Science Foundation Faculty Early Career Development Award in 2009, and the Paul E. Torgersen Graduate Research Excellence Award in 2002. He holds several U.S. patents in MEMS sensors and actuators. He serves as an Associate Editor of Nonlinear Dynamics, the Journal of Computational and Nonlinear Dynamics, Meccanica, and the Journal of Vibration and Control. $\mathrm{He}$ is a member of the American Society of Mechanical Engineers and IEEE. 